\title{
Direct and Indirect Consequences of Decision Situations in Managers in Cellular Companies
}

\author{
MUHAMMAD NA VEED RIAZ \\ Department of Psychology, University of Sargodha. \\ Email: naveed.riaz@uos.edu.pk \\ Tel: +923007714217
}

\author{
HAFIZ MUHAMMAD ZEESHAN IQBAL \\ Department of Psychology, University of Sargodha. \\ Email: zeeshan.iqbal27@yahoo.com \\ Tel: +923036621155
}

\section{GULNAZ MURTAZA}

Riphah Institute of Clinical and Professional Psychology,

Riphah International University Lahore.

Email: gulnazmurtaza101@gmail.com

Tel: +923433503707

\begin{abstract}
The direct and indirect consequences of decision situations in cellular companies were investigated in this research. Prior literature suggests that usually two types of decisions are made in the modern organizations broadly categorized as programmed and non-programmed decisions. Study was conducted which focused on examining the direct effect and indirect effect and (through programmed and nonprogrammed decisions) on subsequent decision styles of managers which were rational and intuitive. Three scales were used for data collection from managers in cellular companies $(N=400)$. Hierarchical regressions confirmed that decision situations have both direct and indirect effect on the decision styles of managers.
\end{abstract}

Keywords: Certainty, Uncertainty, Programmed, Non-Programmed Decisions, Rational Style, Intuitive Style.

\section{Introduction}

Decision-making is the total task of a manager (Singh, 2001). Decisions in organizations are broadly classified into two categories including programmed and non-programmed decisions (Simon, 1977). The Theory of Decision-Making Situations (Griffin, 2011) posits that decisions are made in both of the certain and uncertain situations (Griffin, 2011). In the times of certainty, managers have to make programmed decision and therefore they adopt rational decision-making style. Contrary in time or uncertainty, managers are required to make non-programmed decision and consequently managers select intuitive decisionmaking style (Scott \& Bruce, 1995; Singh, 2001). More specifically, choice of a decisional style is greatly dependent on the type of decision-programmed or non-programmed-to be made rather than personal preferences for a decision-making style (Spicer \& Sadler-Smith, 2005). 
Programmed decisions are the decisions manger make in response to repetitive and routine problems. Nonprogrammed decisions are made for novel and unstructured problems that are complex in nature and extremely important. The nature of the problem, how frequently it arises, and the underlying degree of uncertainty dictate at what level of management the decision should be made. Middle managers in most organizations make both types of decisions whereas non-programmed are made by top management and programmed are made by lower management (Singh, 2001).

\section{Literature Review}

Programmed and non-programmed decisions can be personal or organizational (Singh, 2001). However, in the present study only organizational decisions faced by managers in the job settings are taken into consideration. In spite of the greater importance of decisions in organizations, no valid and reliable instrument is developed till date to measure these decisions. The present study bridged this gap. The present study is divided into two parts, in the first part Organizational Decisions Scale is developed to measures decision types whereas in the second part, main study is conducted for model testing.

The present study has integrated three models of decision sciences in a single coherent investigation. Model of Decision Situations in Organizations by Griffin (2011), Model of Decision Types by Simon (1997) and Typology of Decision Styles by Scott and Bruce (1995) is integrated in this investigation. The underlying research questions are related to the premise that two major decision situations including certainty and uncertainty require programmed and non-programmed decisions and while making these decisions the managers select rational and intuitive decision-making style respectively. The present study is an attempt to investigate that decision types (programmed and non-programmed) mediates between decision situations (certainty and uncertainty) and decision styles (rational and intuitive).

\section{Objectives}

1. To examine the effect of decision situations and decision types on decision making styles.

2. To find out the direct and indirect effect of decision situations on decision making styles.

\section{Hypotheses}

1. Certainty is likely to predict rational style whereas uncertainty is likely to predict intuitive style.

2. Certainty is likely to predict programmed decisions whereas uncertainty is likely to predict nonprogrammed decisions.

3. Programmed decisions likely to predict rational decision-making style whereas non-programmed decisions likely to predict intuitive decision-making style.

4. Programmed decisions likely to mediate between certainty and rational decision-making style.

5. Non-programmed decisions likely to mediate between uncertainty and intuitive decision-making style.

\section{Methodology}

It was a correlational research in which data was collected through purposive sampling technique using cross-sectional design of survey research. Sample comprised of managers in cellular companies $(N=400)$ collected from Islamabad and Lahore. For the purpose of data collection, information and facilitation centers / franchises of the cellular companies were visited including Telenor, JAZZ, Ufone, and Zong situated in different areas of Islamabad and Lahore.

Rationale of collecting information from cellular companies (services providing organizations) was in line with the suggestions of Field (2005) that services providing organizations are under investigation of the 
modern researchers contrary to past researchers who focused industry. In the main study three self-report measures were used including Organizational Decisions Scale (ODS), Decision Situations Scale (DSS) and General Decision-Making Styles Questionnaire (GDMSQ). GDMSQ (Scott \& Bruce, 1995) were used for data collection.

\section{Analysis}

Table No 1: Psychometric Properties and Pearson Correlation in Variables

\begin{tabular}{|c|c|c|c|c|c|c|}
\hline Variables & 1 & 2 & 3 & 4 & 5 & 6 \\
\hline 1. Certainty & $(.80)$ & -.10 & $.52 * * *$ & $-.48 * * *$ & $.41 *$ & $-.51 * *$ \\
\hline 2. Uncertainty & & $(.84)$ & -.11 & $.81 * * *$ & $-.35 * * *$ & .10 \\
\hline 3. Programmed decisions & & & $(.88)$ & -.05 & $.21 * *$ & $.368 * *$ \\
\hline 4. Non programmed decisions & & & & $(.80)$ & $-.36 * *$ & $-.13^{*}$ \\
\hline 5. Rational decision-making style & & & & & $(.89)$ & $-.42 * *$ \\
\hline 6. Intuitive decision-making style & & & & & & $(.82)$ \\
\hline 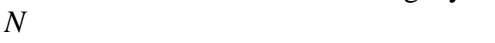 & 400 & 400 & 400 & 400 & 400 & 400 \\
\hline$M$ & 35.41 & 29.10 & 31.21 & 30.25 & 21.58 & 20.58 \\
\hline$S D$ & 8.25 & 6.27 & 5.21 & 8.15 & 3.24 & 3.12 \\
\hline Potential range & $9-45$ & $9-45$ & $8-40$ & $8-40$ & $5-25$ & $5-25$ \\
\hline Actual range & $19-40$ & $23-41$ & $15-38$ & $13-39$ & $10-22$ & $14-20$ \\
\hline Skewness & -.15 & .27 & -.34 & -.95 & -.42 & -.32 \\
\hline Kurtosis & -.24 & .22 & -.23 & -.10 & .85 & .14 \\
\hline
\end{tabular}

$* p<.05 . * * p<.01 . * * * p<.001$.

Results reveal that all the scales have greater than .80 reliability coefficients which indicate that the scale have satisfactory internal consistency. The values of skewness and kurtosis for all variables are less than +1 and -1 which indicates that data is normally distributed. Results of the Pearson correlation indicate that correlation coefficients are in theoretically consistent directions.

Table 2: Linear regression analysis showing the effect of predictors on outcomes

\begin{tabular}{|llll|}
\hline Predictors & Model $B$ & & Outcome \\
\hline Constant & $25.15^{* * *}$ & & Rational decisions \\
Certainty & $.16^{* * *}$ & & \\
$R^{2}$ & & .06 & \\
$F$ & & $18.41^{* * *}$ & \\
\hline Constant & $21.10^{* * *}$ & & Intuitive decisions \\
Uncertainty & $.19^{* * *}$ & & \\
$R^{2}$ & & .09 & Programmed decisions \\
$F$ & & $19.42^{* * *}$ & \\
\hline Constant & $19.22^{* * *}$ & & \\
Certainty & $.10^{*}$ & & \\
$R^{2}$ & & .04 & Non-programmed decisions \\
$F$ & & $10.52^{*}$ & \\
\hline Constant & $20.28^{* * *}$ & & \\
Uncertainty & $.18^{* * *}$ & & \\
$R^{2}$ & & .06 & \\
$F$ & $18.14^{* * *}$ & & \\
\hline Constant & $.08^{* *}$ & & \\
Programmed decisions & & .04 & \\
$R^{2}$ & & & \\
$F$ & $19.17^{* * *}$ & & \\
\hline Constant & $.10^{* *}$ & & \\
Non-programmed decisions & & $10.15^{* *}$ & \\
$R^{2}$ & & \\
$F$ & & & \\
\hline
\end{tabular}


Table 3: Mediation of Decision Types Between Decision Situations and Decision-Making Styles

\begin{tabular}{|c|c|c|c|c|}
\hline \multirow{2}{*}{ Predictor } & \multirow[b]{2}{*}{ Model $1 B$} & & Model 2 & \multirow{2}{*}{ Outcome } \\
\hline & & & $B$ & \\
\hline (constant) & $18.21 * * *$ & & $15.46^{* * *}$ & Rational \\
\hline Certainty & $.16^{* * *}$ & & $.10^{*}$ & \\
\hline Programmed decisions & & & $.16 * *$ & \\
\hline$R^{2}$ & .06 & .09 & & \\
\hline$F$ & $19.52 * * *$ & $15.24 * * *$ & & \\
\hline$\Delta R^{2}$ & & .03 & & \\
\hline$\Delta F$ & & $10.82 * *$ & & \\
\hline (constant) & $30.24 * * *$ & & $21.54 * * *$ & Intuitive \\
\hline Uncertainty & $.51 * * *$ & & $.23 *$ & \\
\hline Non-programmed decisions & & & $.47 * * *$ & \\
\hline$R^{2}$ & .22 & .08 & & \\
\hline$F$ & $34.25 * * *$ & $14.28 * * *$ & & \\
\hline$\Delta R^{2}$ & & .14 & & \\
\hline$\Delta F$ & & $11.24 * * *$ & & \\
\hline
\end{tabular}

\section{Discussion}

The present study was carried out to test direct and indirect hypotheses regarding decision types in organizations. The study examined the antecedents and consequences of programmed and non-programmed decisions in cellular companies. The antecedents comprised of decisions situations including certainty and uncertainty. The outcomes were decisions making styles including rational and intuitive decisions. Besides this direct effect, the study also tested the medication hypotheses. The study examined the mediation of programmed and non-programmed decisions between decision situations and decisions styles in cellular companies.

The first hypothesis "certainty is likely to predict rational decision-making style whereas uncertainty is likely to predict intuitive decision style" was supported. The findings are consistent in the prior research conducted in the services providing organizations of Pakistan (Riaz, 2015). The prior research suggests that in the conditions of certainty marked by more time availability and comparative easy decisions (Griffin, 2011), it is more appropriate to use rational decision-making style which is characterized by time-taking logical analysis and careful evaluation of all possible alternatives of a decision (Scott \& Bruce, 1995). Contrary, uncertainty marked by urgency and less time availability requires more prompt decisions (Griffin, 2011) instead of time-consuming rational analysis. Consequently, intuitive decision-making style is batter alternative which provides an opportunity to make quick decision (Scott \& Bruce, 1995). In sum, choice of rational or intuitive decisions is grounded in the underlying situations in which decisions have to be made.

The second hypothesis "certainty is likely to predict programmed decisions whereas uncertainty is likely to predict non-programmed decisions" was supported. In organizations, decisions are made in two extreme situations e.g. either in the conditions of complete information availability characterized by certainty or in the complete absence of information characterized by uncertainty (Griffin, 2011). In times of certainty which is characterized by low ambiguity, programmed decisions are made in which the probability of making wrong decision is reasonably low and decisions are routine-based and repetitive (Griffin, 2012; Lawson \&Shen, 1998). Contrary to programmed decisions which are made in sure conditions, the uncertainty is characterized by high level of ambiguity in which usually non-programmed decisions are made which are rather unique and novel. Due to the unique nature of decisions which do not involves familiar details, the tendency of making errors and wrong decisions is very high (Bartol et al., 1998; Griffin, 2011). In such conditions of emergency, decision makers are required to make non-programmed decisions for organizations. 
The third hypothesis "programmed decisions are likely to predict rational decision-making style whereas non-programmed decisions are likely to predict intuitive decision-making style" was supported. Programmed decisions which are made in certainty - characterized by complete information availability-require well-informed rational decisions. Thus, while making programmed decisions; rational choices are made by the decision makers. Rational decisions are characterized by collecting and analyzing information to make ideal decisions (Scott \& Bruce, 1995). Non-programmed decisions-which are quite unfamiliar, unstructured, exceptional and unusual-require intuitive decisions which are made in the times of uncertainty (Stoner et al., 1994; Bergstrand, 2001; Callan\& Proctor, 2000). Intuitive decision-making style makes prompt decisions possible (Kahneman, 2003). Thus, the urgency caused by non-programmed decisions is well-responded in time by using intuitive decision-making style (Bergstrand, 2001).

The fourth hypothesis "programmed decisions mediate between certainty and rational decision-making style" was supported. Besides the direct effect, the findings confirmed the indirect path. Programmed decisions mediated between certainty and rational decision-making style. The findings illustrated that in the times of certainty, decision makers make programmed decisions. Consequently, they make use of rational decision-making style because more time is available for making solutions of well-structured problems. Thus, the decision makers try to maximize the benefits of their decisions by making ideal choices through incorporating logic, rationality and pre-determined decision rules in their decisions (Bartol et al., 1998; Scott \& Bruce, 1995). Consistent decision research confirmed the superiority of rational decisions in predicting numerous positive outcomes in the modern organizations of Pakistan (Hassan, Hayee, \&Riaz, 2010; Riaz, Riaz, \&Batool, 2014; Riaz, 2015).

The fifth hypothesis "non-programmed decisions mediate between uncertainty and intuitive decisionmaking style" was supported in the present study. Although the programmed decisions are sample and easy, most significant managerial decisions are non-programmed and involve significant uncertainty (Robbins, Bergman, Stagg, \& Coulter, 2000; Lawson \& Shen, 1998; Stoner et al., 1994). Programmed decisions are operational and procedural in nature that can be made even with the use of rulebook. However, the non-programmed decisions are more strategic in nature which determines the destiny of the organizations (Singh, 2001).

In the present study, non-programmed decisions perfectly mediated between uncertainty and intuitive decision-making style which confirms that in the times of uncertainty, managers make non-programmed decisions for which intuitive style is used. Intuitive decision-making style increases awareness self and environmental awareness (Singh \& Greenhaus, 2004) and predicts innovativeness (Thunholm, 2004) which is requirement of an uncertain decision. In times of high ambiguity, uncertainty and blind risks, intuitive style facilitates decision makers in taken quick decisions (Callan \& Proctor, 2000).

\section{Implications}

Overall research is a worthy addition in the existing body on knowledge in Organizational Behavior, Industrial Organizational Psychology in general and Decision Sciences in particular. The study proved that decision situations play a leading role in degerming the decisions of the managers.

\section{Conclusion}

Results of the linear regression analysis revealed significant effect of predictor variables of outcome variables. The direction of prediction is also in line with the hypothesized directions. Results of the hierarchical regression indicate that programmed decisions mediated between certainty and rational style whereas non-programmed decisions mediated between uncertainty and intuitive style. In both cases, evidences for partial mediation were collected as in Model 1 and 2, regression weights were reduced but remained significant. 


\section{References}

Bartol, K., Mattin D., Tein, M., \& Matthews, G. (1998). Management: A Pacific Rim focus, Sydney: McGraw-Hill.

Bergstrand, B. (2001). Situating the estimate: naturalistic decision-making as an alternative to analytical decision-making in the Canadian Forces. Retrieved on June 13, 2015, from http:// wps.cfc.dnd.ca/irc/nh9798/0021

Callan, J., \& Proctor, S. (2000). Tactical decision-making under uncertainty: Experiments I, and II. Technical Report, 1821, April, Pacific Science and Engineering Group. California: SSC San Diego, Inc.

French, V. L. (2005). The personnel management processes. Boston: Houghton Mifflin Company.

Griffin, R. W. (1211) Management: Principals and applications (9th ed.). Boston: Houghton Mifflin.

Hassan, B., Hayee, A. A., \&Riaz, M. N. (2010). Role of self-regulation and decision-making at banks. Berlin: Lambert.

Kahneman, D. (2003). Maps of bounded rationality: Psychology for behavioral economics, American Economic Review,93(5), 1449-1475.

Lawson, R \& Shen, Z. 1998, Organizational Psychology: Foundations and Applications, Oxford University Press, Oxford

Riaz, M. N. (2015). Leadership styles as predictors of decision-making styles: moderating role of decision related factors (Unpublished PhD dissertation). Department of Psychology, International Islamic University Islamabad.

Riaz, M. N., Riaz, M. A., \&Batool, N. (2012). Personality types as predictors of decision-making styles. Journal of Behavioral Sciences, 22(2), 99-114.

Robbins, S.P., Millett, B., Cacioppe, R., \& Marsh, T.W. (1998). Organizational Behavior (2nd ed.). Sydney: Prentice Hall.

Scott, S. G., \& Bruce, R. A. (1995). Decision-making style: The development and assessment of a new measure, Educational and Psychological Measurement, 55, 818-831.

Simon, H. (1977). Review of The New Science of Management Decision. Administrative Science Quarterly, 342-351.

Simon, H. A. (1997). An empirically based microeconomics. Cambridge, UK: Cambridge University Press.

Singh, N. (2001). Organizational behavior: Concepts, theory and practices. New Delhi: Deep \& Deep Publications.

Singh, R., \& Greenhaus, J. H. (2004). The relation between career decision-making strategies and personjob fit: A study of job changers. Journal of Vocational Behavior, 64(1), 198-221.

Spicer, D. P., \& Sadler-Smith, E. (2005). An examination of the general decision-making style questionnaire in two UK samples. Journal of Managerial Psychology, 20(2), 137-149.

Stoner, F. A., Yetton, W., Craig, F. J., \& Johnston D. K. (1994). Management (2nd ed.). Sydney: Prentice Hall.

Thunholm, P. (2004). Decision-making style: Habit, style or both? Personality and Individual Differences, 36(4), 931-944. 